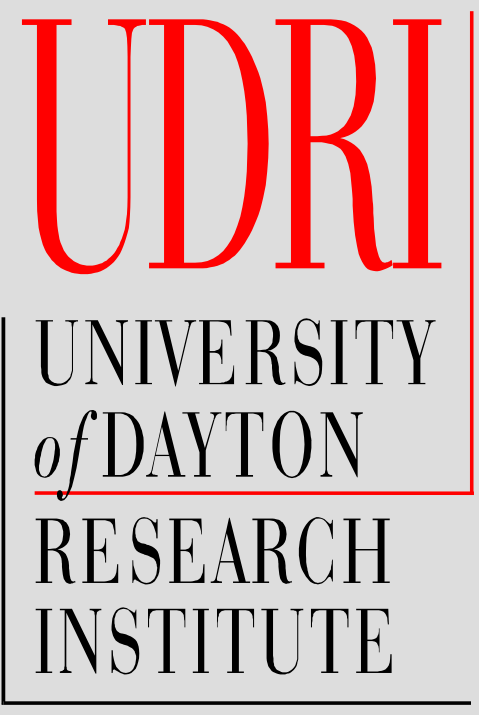

Report

ELEVATED

TEMPERATURE

SENSORS FOR ON-LINE

CRITICAL EQUIPMENT

HEALTH MONITORING

May 2006 


\title{
Elevated Temperature Sensors for On-Line Critical Equipment Health Monitoring
}

\author{
Annual Report \\ May 2006 \\ Contract No. DE-FG26-02NT41534
}

Prepared for:

U.S. Department of Energy

National Engergy Technology Laboratory

Pittsburgh, PA 15236

Prepared by:

James Sebastian, P.E.

STRUCTURAL INTEGRITY DIVISION

300 College Park

Dayton, OH 45469-0120 
TITLE: ELEVATED TEMPERATURE SENSORS FOR ON-LINE
CRITICAL EQUIPMENT HEALTH MONITORING

REPORT TYPE: Annual Report

REPORTING

PERIOD:

January 2005 - December 2005

PI:

James Sebastian

STUDENTS:

Michael Frede, Matthew Pacyna

DATE REPORT

ISSUED:

May 2006

GRANT NO:

DE_FG26-02NT41534

INSTITUTION: University of Dayton Research Institute Structural Integrity Division

300 College Park

Dayton, OH 45469-0120

(937) 229-4417

(937) 229-3712 (Fax)

sebastian@udri.udayton.edu

Technical Report\# UDR-TR-2006-00130 
This report was prepared as an account of work sponsored by an agency of the United States Government. Neither the United States Government nor any agency thereof, nor any of their employees, makes any warranty, express or implied, or assumes any legal liability or responsibility for the accuracy, completeness, or usefulness of any information, apparatus, product, or process disclosed, or represents that its use would not infringe privately owned rights. Reference herein to any specific commercial product, process, or service by trade name, trademark, manufacturer, or otherwise does not necessarily constitute or imply its endorsement, recommendation, or favoring by the United States Government or any agency thereof. The views and opinions of authors expressed herein do not necessarily state or reflect those of the United States Government or any agency thereof. 
This report summarizes the third year of the current research program. The objective of the program is to improve high temperature piezoelectric aluminum nitride (AIN) sensor technology to make it useful for instrumentation and health monitoring of current and future electrical power generation equipment. These improvements are aimed primarily at extending the temperature range of the sensor from approximately $700^{\circ} \mathrm{C}$ to above $1000^{\circ} \mathrm{C}$, and investigating ultrasonic coupling to objects at these temperatures and tailoring high temperature coupling for use with the sensor. The chemical vapor deposition (CVD) AIN deposition process was successfully transferred from film production on tungsten carbide substrates to titanium alloy and silicon carbide ( $\mathrm{SiC}$ ) substrates in the first year of the program, and additional substrates were evaluated. In the second year of the program, additional substrate research was performed with the goal of improving the performance of using SiC substrates, and coupling research was continued. During the current reporting period, new porous SiC substrates were used to improve adhesion, but films robust enough for sensor implementation were not achieved. Gold leaf was selected as the optimum metal foil high temperature couplant. In August, a new family of high temperature piezoelectric materials came to the attention of the program. Samples of langasite, the most promising member of the family, were obtained and preliminary data showed promise. A nocost extension of the program allowed research to continue with the langasite into 2006. 


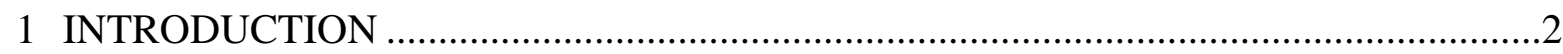

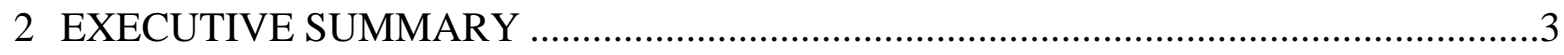

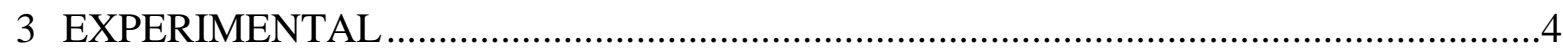

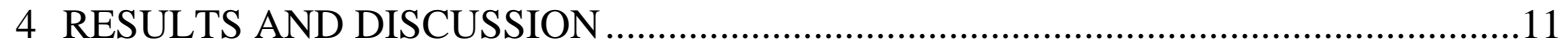

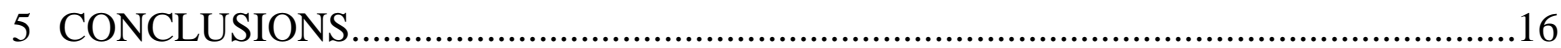




\section{SECTION 1 INTRODUCTION}

In order to use coal-fired electrical power generation equipment to its fullest potential, sensors are required which are capable of monitoring the "health" of critical system components. Such sensors can alert an operator to impending problems, if any, while reducing the need to shut down equipment for inspection. Benefits of health monitoring include reduced down time for inspection or unplanned outages. For equipment operating at high temperatures, this will also likely reduce thermal cycles and associated fatigue or wear. Equipment that can benefit from such health monitoring includes dynamic systems, such as turbine engines, as well as static systems such as gasifiers, process piping, or other chemical processing facilities.

Past research conducted at the University of Dayton into the properties and behavior of Aluminum Nitride (AlN), a high temperature piezoelectric material, indicated that this material has a high potential for providing a basis for sensors that can be used for elevated temperature health monitoring, up to at least $1000^{\circ} \mathrm{C}\left(1800^{\circ} \mathrm{F}\right)$. The most straightforward implementation of such AlN sensors is as ultrasonic transducers, for example as a thickness monitor in a critical region of a metal or ceramic component exposed to corrosive or erosive conditions. Ultrasonic thickness gages are widely available commercially for room temperature measurements. Ultrasonic waves may additionally be used to monitor bonds, such as that between a metal and a ceramic, as found in thermal and environmental barrier coatings commonly found in power generation equipment.

The first year of this three-year effort focused on laying the groundwork for extending the sensor technology to the high temperature $\left(>1000^{\circ} \mathrm{C}\right)$ regime. The second year continued to extend this groundwork, including further investigations of high temperature coupling and substrate research for the AlN films. The third year brought coupling research to a successful conclusion. In addition, continued research into AlN film deposition confirmed the desirability of silicon carbide substrates, with porous $\mathrm{SiC}$ being the most promising. Deposition on the porous $\mathrm{SiC}$ was achieved, but as with the monolithic SiC, good adhesion of the AlN films was not achieved

In addition to the required poster at the University Coal Research annual review meeting, results from this research were presented at the Review of Quantitative Nondestructive Evaluation (QNDE), Brunswick, Maine, and the American Society for Nondestructive Testing (ASNT) annual meeting in Columbus, $\mathrm{OH}$. Following up on leads generated at QNDE led to the discovery of a new high temperature piezoelectric material, langasite (LGS) which has much promise for overcoming the limitations of the AlN films and operating at ultrasonic frequencies below $15 \mathrm{MHz}$, the desirable range for most health monitoring and ultrasonic sensor applications. In addition, the langasite will not oxidize when used in air at high temperatures above the $700^{\circ} \mathrm{C}$ level where AIN requires protection. Samples of the LGS were obtained and preliminary testing had encouraging results for future transducer development. 


\section{SECTION 2 \\ EXECUTIVE SUMMARY}

The goal of this project is to develop sensors that can be used at elevated temperatures, up to $1000^{\circ} \mathrm{C}$, in power generation equipment. The primary target application for these sensors is equipment health monitoring. Historically, ultrasonic sensors have been used to evaluate properties of solid and fluid materials. Detected flaws may include cracks, voids, inclusions, porosity, or other discontinuities. Additionally, ultrasound is used in flowmeters, proximity sensors, and for material thickness measurements.

Conventional ultrasonic transducers and instrumentation are temperature limited because the piezoelectric materials used in the transducer cannot operate above their Curie point or de-poling temperature. Operation above $100^{\circ} \mathrm{C}$ is considered "high temperature" with special requirements met by quartz or tourmaline transducers up to $\sim 450^{\circ} \mathrm{C}$, or complicated delay lines with complex cooling requirements (and usually) exposure times measured in seconds. Laser-based ultrasound and electromagnetic acoustic transducers (EMATs) are also used at high temperatures but are expensive or complicated. In addition, coupling the ultrasonic energy from the transducer into the test object becomes much more difficult above $100^{\circ} \mathrm{C}$.

The current project was directed toward developing ultrasonic transducers based on piezoelectric aluminum nitride (AlN) films to enable the use of ultrasound for material evaluation at temperatures exceeding $1000^{\circ} \mathrm{C}$. The majority of the project was spent trying to advance the AlN film deposition process to produce a film- substrate combination that could meet the $1000^{\circ} \mathrm{C}$ operating target temperature. This goal was not met after much effort due to the lack of AlN adhesion on a number of candidate substrates, with much of the work focusing on various forms of silicon carbide. However, an alternative approach using langasite crystals as the core of ultrasonic transducers was identified and preliminary testing on this material was performed. The originally planned transducer demonstration project was scaled down into an advanced test of a langasite-based transducer design.

The results from the first year's literature survey on elevated temperature ultrasonic coupling pointed toward the use of molten glass or metal foil as a couplant material. These methods were further investigated and demonstrated experimentally in the second year. The use of molten glass was inconsistent; it worked but tended to react with materials in contact with it, as well as the air. Metal foils showed much more promise as a robust couplant, beginning with aluminum foil at lower temperatures and extending on to gold at higher temperatures. Gold leaf was selected as the optimum solution for coupling. 


\section{SECTION 3 \\ EXPERIMENTAL}

\section{Piezoelectric AlN Film Deposition}

In the first two years of the program, the existing chemical vapor deposition (CVD) process for making piezoelectric AlN films was reconstituted and used to deposit films on tungsten carbide substrates, duplicating previous efforts. It was then advanced to new substrate materials, of which silicon carbide ( $\mathrm{SiC}$ ) showed the most promise for high temperature, broadband transducers. Films were achieved on several SiC materials, but the films exhibited poor adhesion, especially when subjected to thermal cycles as would be expected in a high temperature application.

Film deposition in the third year of the program attempted to overcome this problem with a porous form of SiC, produced by Saint Gobain. The porosity was expected to provide surface roughness to increase the mechanical bond of the AlN with the surface of the substrate, providing improved film adhesion. In addition, pores in the bulk of the material would scatter the sonic energy projected back into the substrate, reducing or eliminating back surface echoes.

Two different forms of the material were investigated- porous SiC as described above, and siliconized porous $\mathrm{SiC}$ which had been infiltrated with molten elemental silicon. An initial deposition on both $\mathrm{SiC}$ materials was promising. The films were well adhered and piezoelectric. The $\mathrm{SiC}$ was conductive enough to provide a back surface electrode. The non-infiltrated porous substrates scattered and attenuated the ultrasonic energy to the point that a coherent back surface echo could not be detected. Initial films are shown in Figure 1, and an ultrasonic signal from a film reflected from the back of a test block is shown in Figure 2. Applying a thermal cycle to several films quickly indicated that the AIN bonding to the siliconized SiC was poor, while the porous material continued to show promise. Thermally cycled films are shown in Figures 3 and 4.

The next step was to obtain additional porous $\mathrm{SiC}$ in the sizes and shapes more desirable for transducer work. A sheet of material was obtained, and cylinders were cut out by abrasive waterjet. AlN deposition on these cylinders was successful and initial adhesion was good, as with the earlier samples. However, as with the other forms of SiC, adhesion was not maintained consistently upon thermal cycling. Varying the surface condition through additional polishing did not solve the adhesion issue. Figures 5 and 6 show an as-deposited film and a film after cycling to only $200^{\circ} \mathrm{C}$ that exhibited a typical, patchy failure mode.

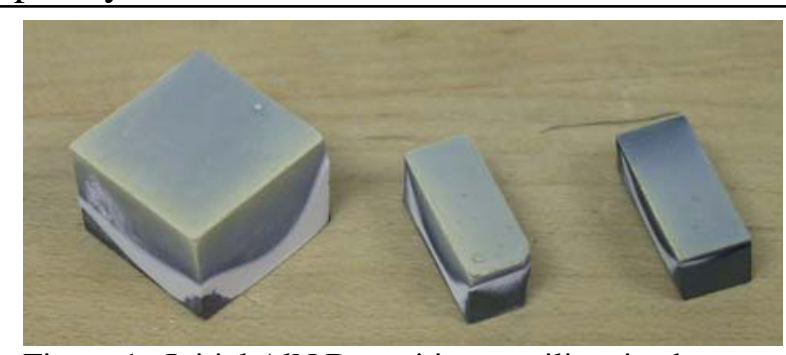

Figure 1. Initial AlN Deposition on siliconized (square) and porous SiC (rectangular).

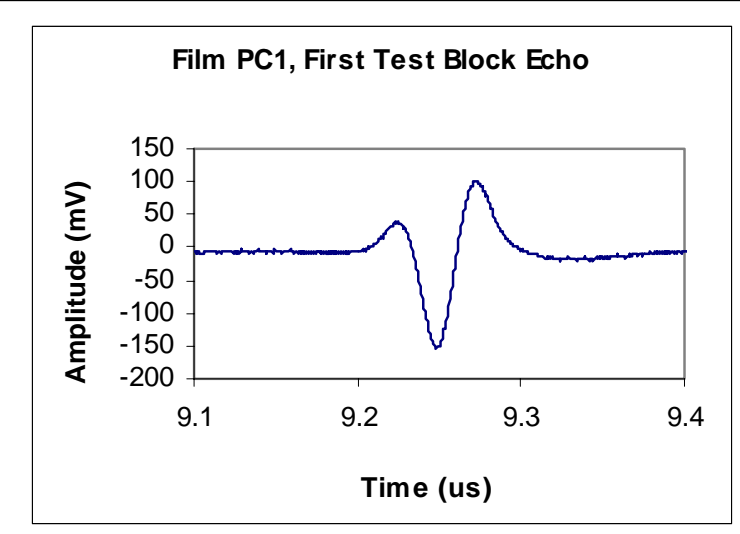

Figure 2. Wideband ultrasonic signal produced by AlN film on porous SiC substrate 

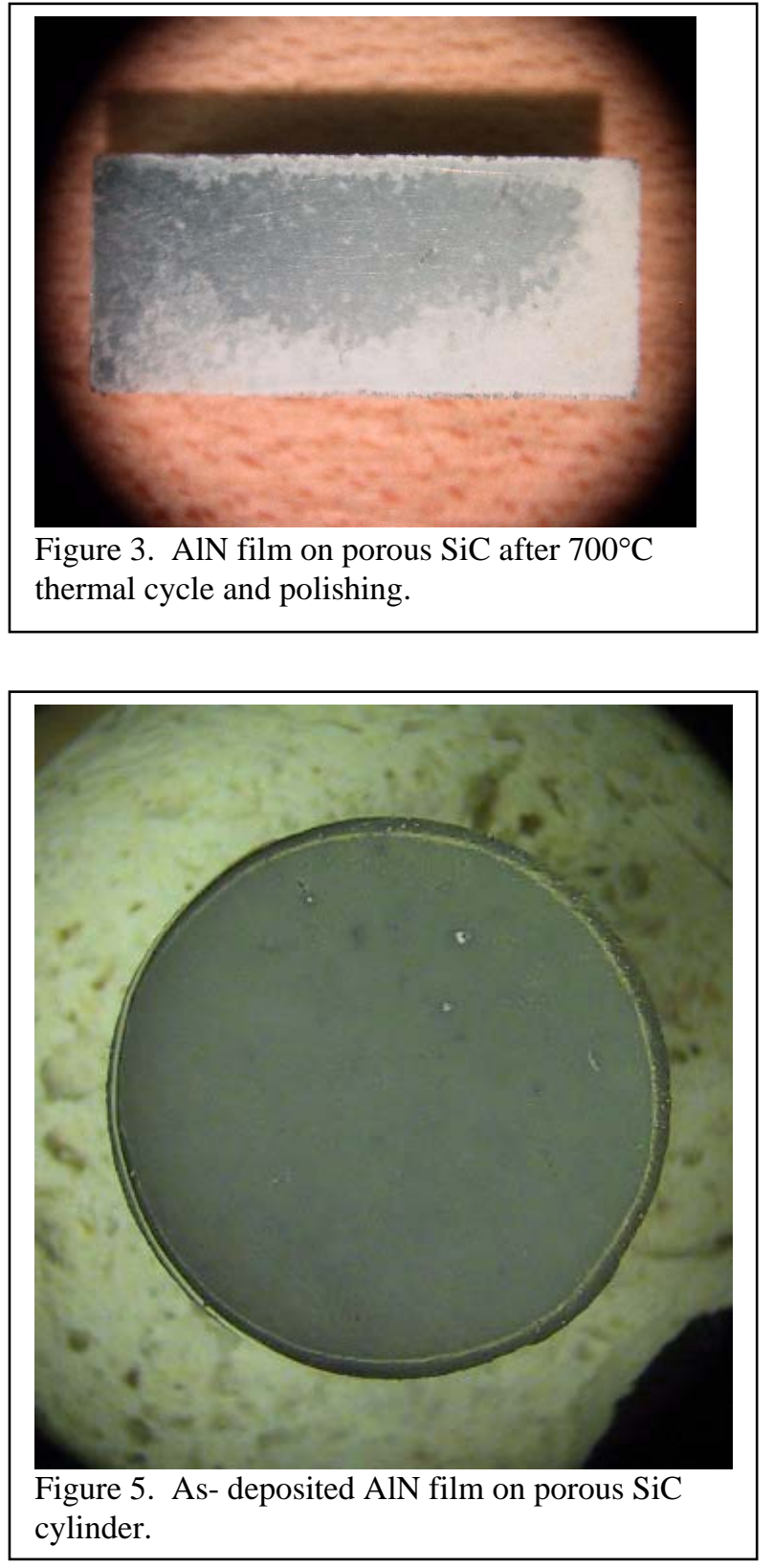

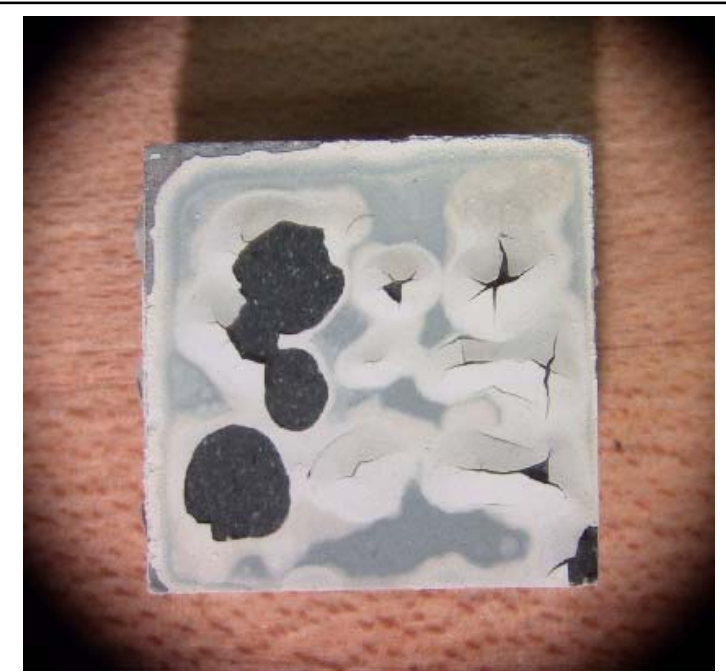

Figure 4. AlN film on siliconized SiC after $700^{\circ} \mathrm{C}$ thermal cycle.

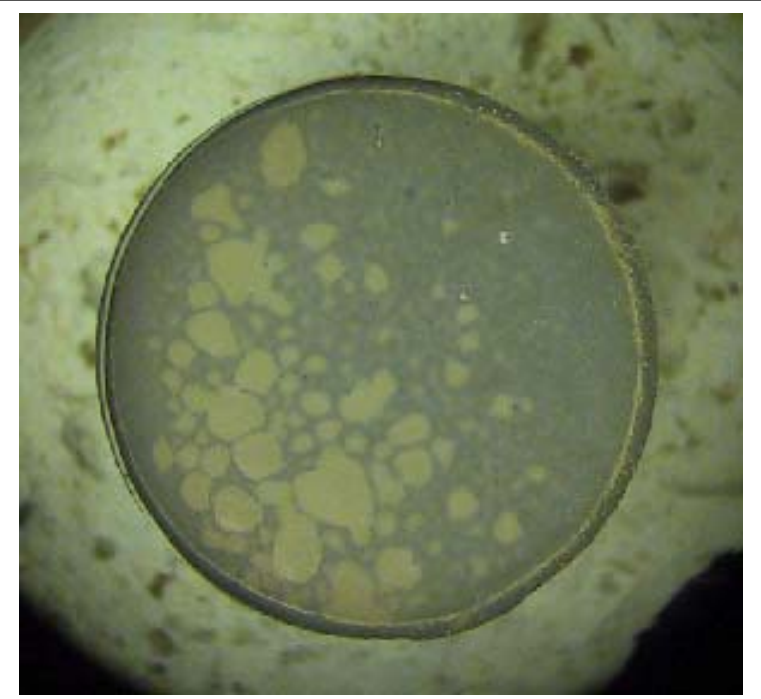

Figure 6. AlN film on porous SiC cylinder after $200^{\circ} \mathrm{C}$ thermal cycle.

A flame spray coating of WC-Cobalt was applied to a WC substrate in an effort to promote adhesion; but deposition was unsuccessful and this process was not carried over to $\mathrm{SiC}$ substrates. After the analysis of the films discussed below, further film deposition efforts were halted in favor of researching alternatives to the AlN films for high temperature piezoelectric sensor cores. 


\section{Piezoelectric AlN Film Evaluation}

Physical evaluation, embodied as film adhesion to the substrate, became the primary evaluation criteria for the films on porous Sic because disbonding during thermal cycling was the predominant failure mode. Most films had good coverage, few or no pinhole defects, and were oriented to be piezoelectric. Film failure from thermal cycling, such as shown above in Figure 6, occurred universally. The onset of damage varied, usually in the $200^{\circ} \mathrm{C}$ to $500^{\circ} \mathrm{C}$ range, although some films maintained adhesion to $700^{\circ} \mathrm{C}$ for one or two cycles. Analysis, consisting of micrographic sectioning and chemical analysis, was performed. It was determined that the AlN deposition was actually occurring in two distinct phases, consisting of a thin, dense layer, followed by a more porous outer layer as shown in Figures 7 and 8.
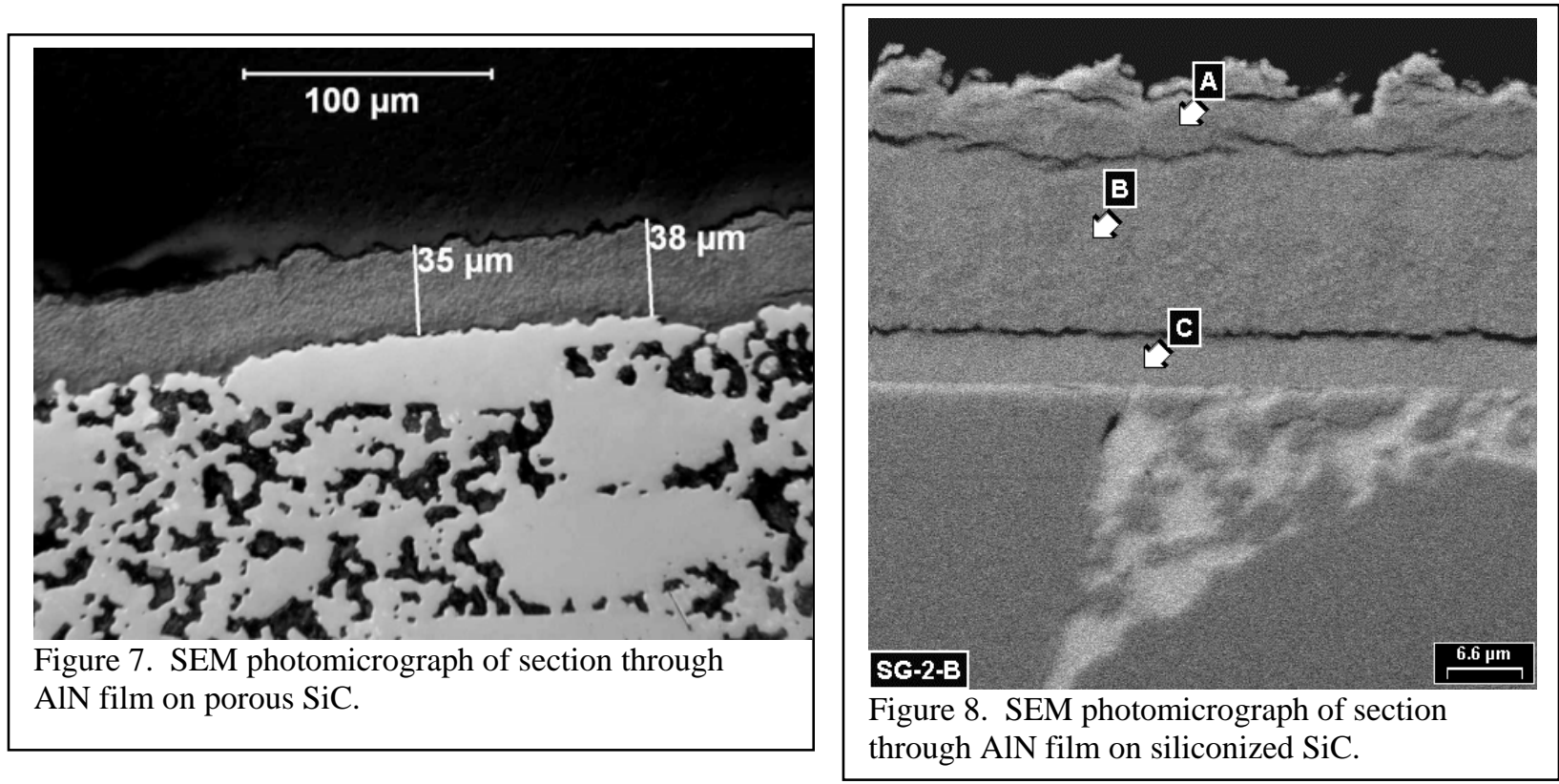

The cracks in a plane parallel to the surface of the substrate visible in Figure 8 were noted in all the samples evaluated.

Additional analysis was performed on the surface of substrates where films had failed due to thermal cycling. Elemental analysis revealed the presence of a substantial amount of oxygen on the surface, likely bound in silicon dioxide. The deposition process was reviewed to insure that oxygen contamination was not occurring during substrate heating and deposition, but no source of contamination was found. Samples prior to thermal cycling were also evaluated using SIMS/Auger to check for contamination after deposition. Table 1 shows the results, indicating that oxygen is present at the surface of the AlN but the concentration quickly falls off with depth. The remaining concentration is still enough to be of concern.

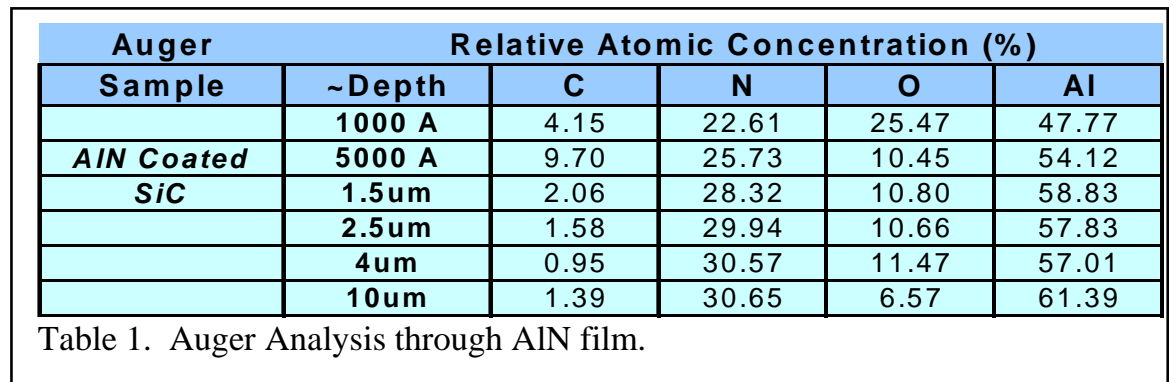


The X-ray diffraction spectrum of a typical AlN film on SiC, shown in Figure 9, indicates it is composed primarily of oriented AlN, with a possible Si-Al intermetallic phase as a minor component, probably due to reaction with the free silicon.

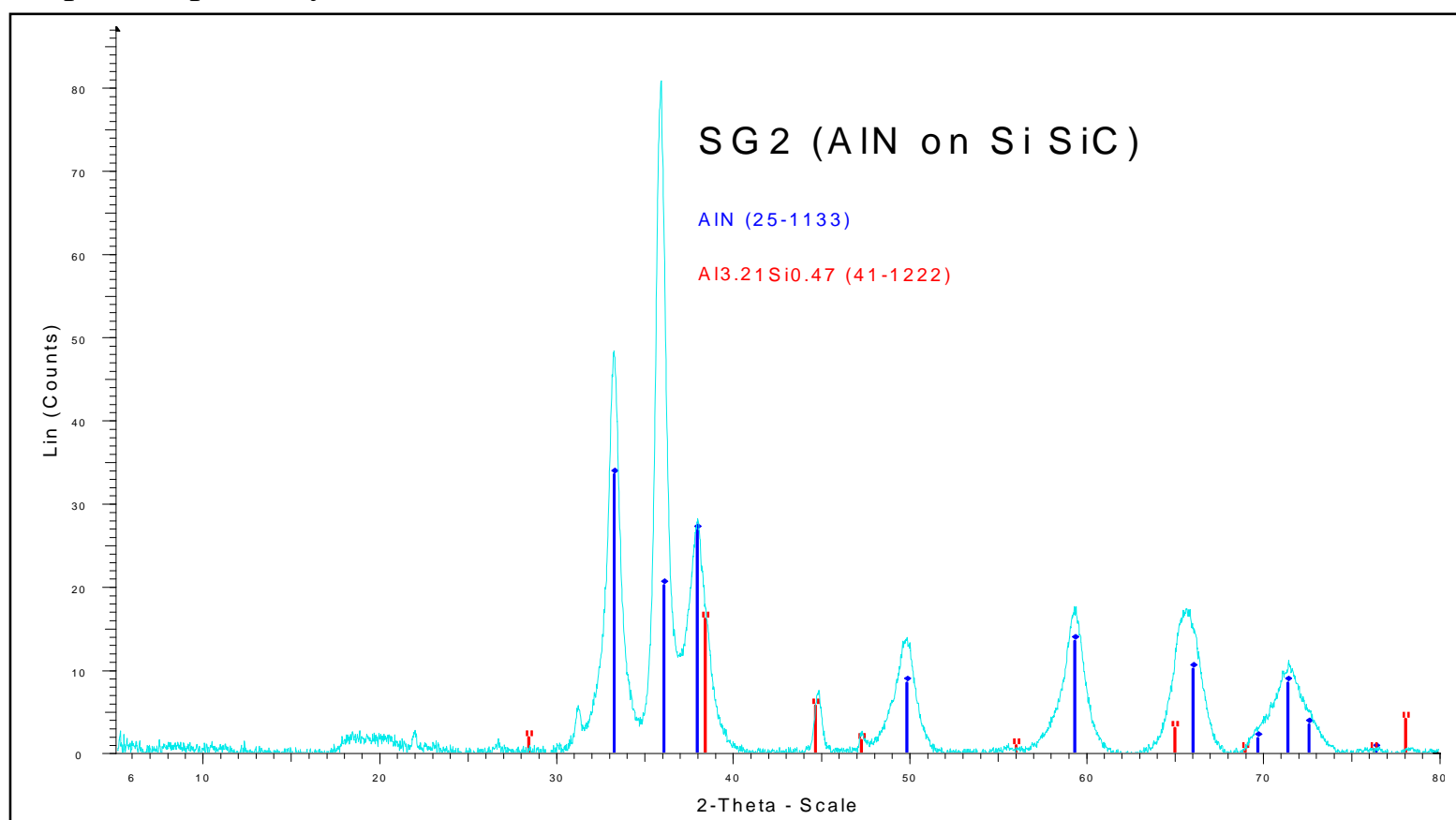

Figure 9. XRD analysis at surface of AIN film.

The SEM allowed the discovery that even films which appeared to survive initial thermal cycles did not do so without substantial microscopic damage. Figure 10 shows an AlN film on siliconized SiC before and after a thermal cycle to $1050^{\circ} \mathrm{C}$ in an inert (argon) atmosphere. The presence of this sort of damage indicates that oxidation from the atmosphere is not a requirement for the damage to occur. The cracking pattern may indicate the boundaries between individual crystal grains, suggesting that thermal strains arise, stressing the film-substrate bond.

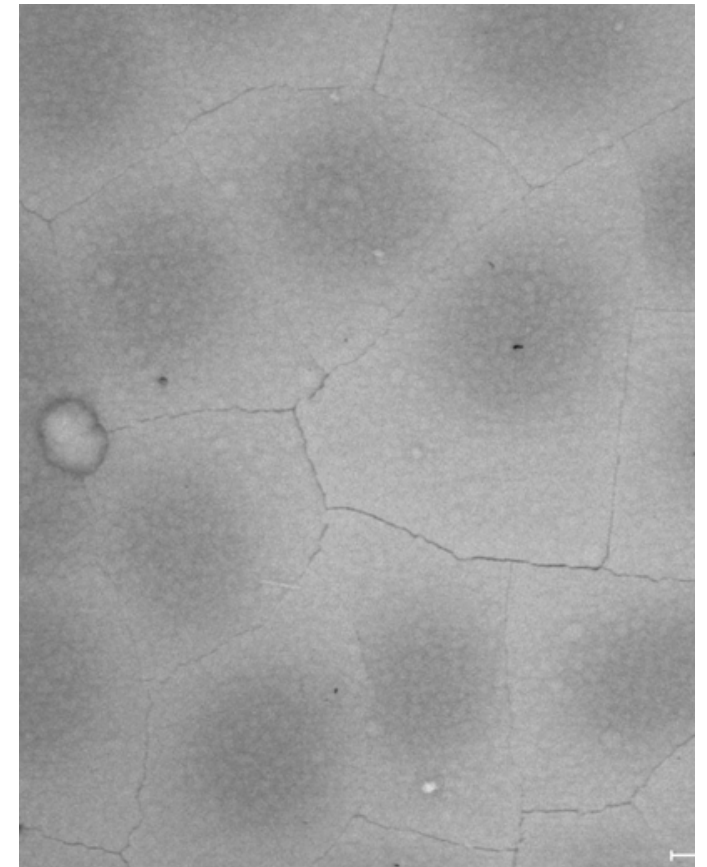

Figure 10. SEM photomicrograph of cracked AlN film on siliconized SiC after thermal cycle. 
As before, testing for ultrasonic properties was performed on "good" films on porous $\mathrm{SiC}$ substrates, using the same apparatus and methodology described in the previous report. The echo from the back surface of the porous substrate was too highly attenuated to be useful, for measurement and so all data for films on porous $\mathrm{SiC}$ was taken on test blocks, such as the 20 $\mathrm{MHz}$ pulse shown in Figure 2. The rapid attenuation of received pulses from two successive echoes is shown in Figure 11. Ultrasonic evaluation of the films on porous substrates was used primarily to show that the films were active before subjecting them to thermal cycling; these films were similar in strength and frequency content to earlier films on tungsten carbide, titanium, and solid SiC substrates.

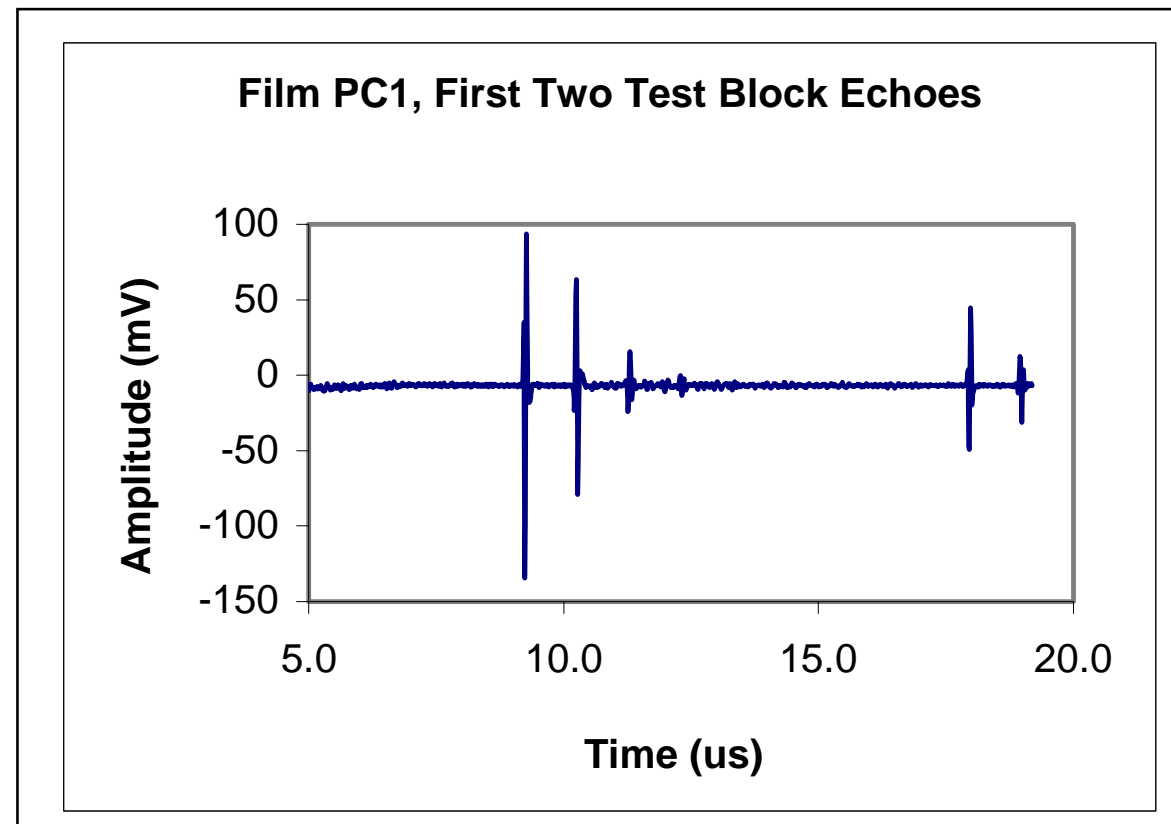

Figure 11. Ultrasonic signal produced by AlN film on porous SiC substrate, showing rapid attenuation of ringing in substrate after reception of each pulse 


\section{High Temperature Ultrasonic Coupling}

The coupling experimentation was essentially completed in the first two years of the program, with metal foil under pressure selected as a good solution to the problem. New work in this area focused briefly on finding a more cost-effective implementation than the gold foil previously selected. Gold leaf, used by artists to give a true golden finish to objects, was obtained. The $24 \mathrm{k}$ leaf is extremely thin $(0.1 \mu \mathrm{m})$ and is thus much less expensive than foil $(\sim 25 \mu \mathrm{m})$. A book of gold leaf such as the one in Figure 12 costs less than $\$ 100$ and contains $\sim 1800 \mathrm{~cm}^{2}$ of gold leaf. Several layers of gold leaf between objects provided good ultrasonic coupling, similar to foil. Handling the leaf is more difficult, however, as it is very delicate. For this reason, plain loose gold leaf was found to be superior to "patent" gold leaf, which is sold adhered to tissue paper for support during handling but is difficult to remove from the paper when not adhered to something else. No adhesives could be used in this work due to high temperatures involved, and evaporating liquids such as water and methanol did not work as alternatives.

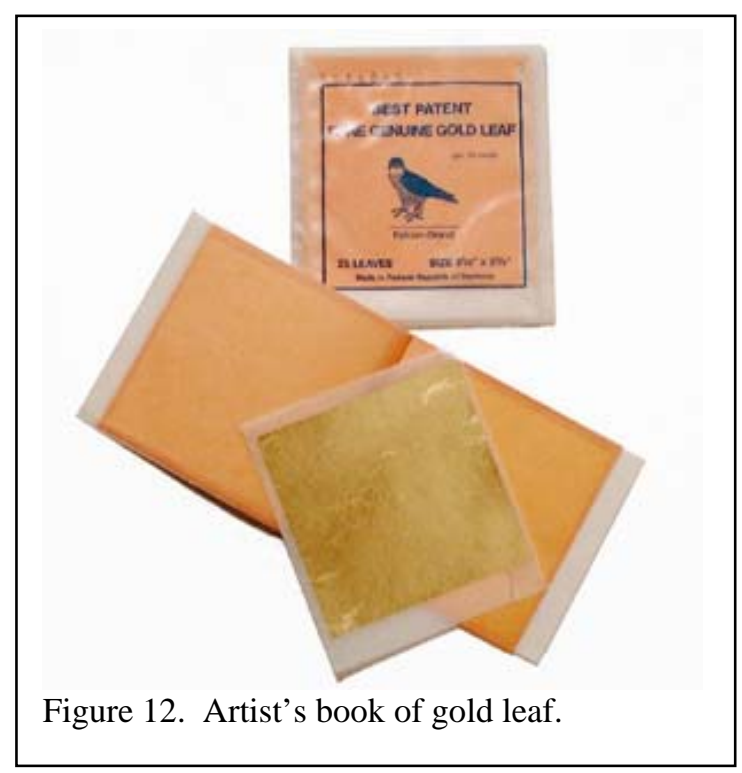

New Crystal Acquisition and Testing

While the overall goal of the program was a high temperature sensor, much of the research in the first 2.5 years of the program focused on advancing the sensor core, consisting of a piezoelectric AlN film deposited on a conductive substrate. Because of the difficulties encountered in AlN film deposition, a reexamination of this approach yielded two possible alternatives. The first alternative was to procure single crystal AlN, but this technology did not yet appear to be practical, with only very limited production available, and dedicated to the semiconductor industry.

A second single crystal material with potential is Langasite (LGS), $\mathrm{La}_{3} \mathrm{Ga}_{5} \mathrm{SiO}_{14}$, a synthetic crystal material. LGS is very chemically stable at elevated temperature and undergoes no phase transformations until it melts at $1470^{\circ} \mathrm{C}$. It has the same crystal structure as alpha-quartz, making it piezoelectric, but the lack of a phase transformation prior to melting means that it has no Curie temperature like quartz. It is available commercially from multiple sources at reasonable cost, and crystals may be obtained cut to any desired thickness (inverse of frequency) and in several orientations. Substituting LGS for the AIN in sensors has the potential to operate at or beyond $1000^{\circ} \mathrm{C}$ for extended periods of time, even in an oxidizing atmosphere.

Samples of LGS were procured from two sources, Axtal (Germany), and Mitsubishi Electronic Materials (Japan). Figure 13 shows a Mitsubishi crystal, which is the translucent orange color 
typical of the LGS. The same crystal in Figure 14, has been cycled to $700^{\circ} \mathrm{C}$ with no apparent oxidation or other effects, and no degradation in signal strength. To evaluate the piezoelectric behavior with temperature, a test was devised where the crystal was placed on a heated platen, a flat electrode was placed on top, and a voltage pulse was applied across the crystal as it would be applied in an ultrasonic transducer. This induced a free resonant vibration through the thickness of the crystal because it is not ultrasonically coupled to a backing material or test material on either face. These vibrations, shown in Figure 15, indicate that the resonant frequency of the 1 $\mathrm{mm}$ thick crystal is about $3 \mathrm{MHz}$. It is therefore acoustically very similar to AlN. The graph in Figure 16 further shows the behavior of this vibration with temperature- the LGS becomes more responsive up to at least $600^{\circ} \mathrm{C}$. This peak is not consistent between different samples of the material, and may be the result of electrode oxidation or other effects not tied to the crystal itself, or may be a softening of the crystal with temperature. Similar behavior is exhibited by the Axtal material, $0.85 \mathrm{~mm}$ thick.

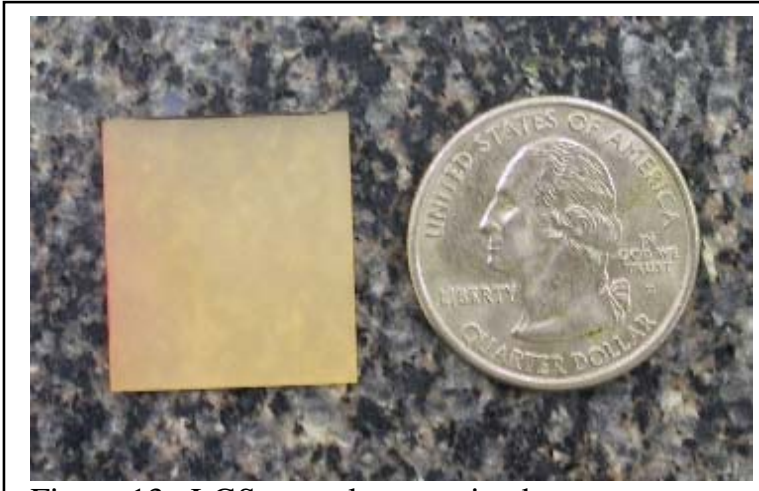

Figure 13. LGS crystal, as received.

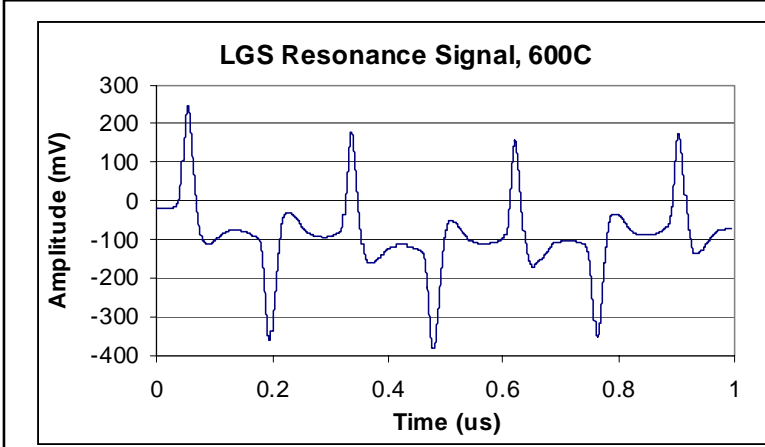

Figure 15. Free vibration piezoelectric resonance in LGS crystal.

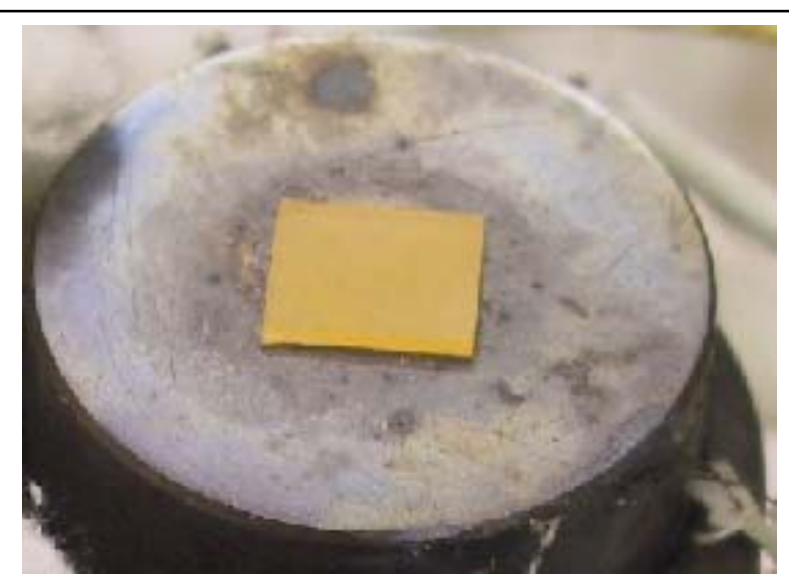

Figure 14. LGS crystal after $700^{\circ} \mathrm{C}$ thermal cycle.

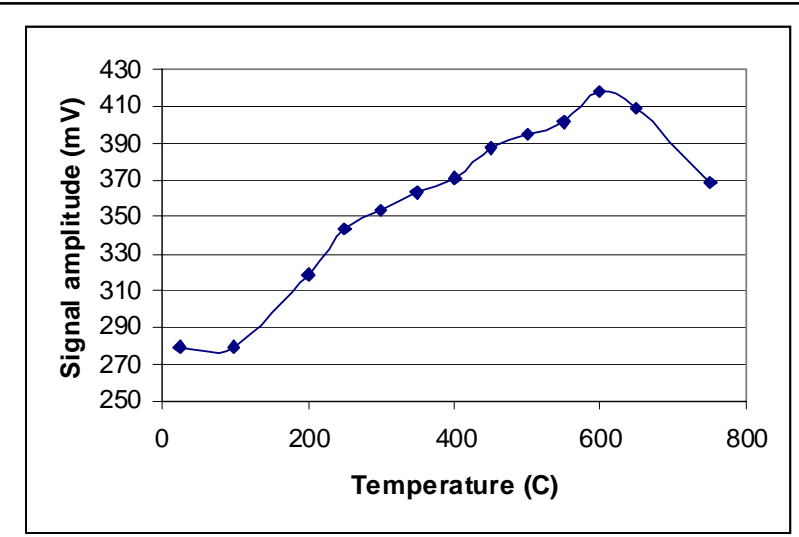

Figure 16. Resonance amplitude in LGS crystal as a function of temperature. 


\section{SECTION 4 \\ RESULTS AND DISCUSSION}

Piezoelectric AIN Film Deposition

Task Description: The deposition of AIN films onto high temperature substrates will be studied and improvement made with respect to process and yield. Disposition of films will initially be done by an elevated temperature chemical vapor deposition process. An alternative deposition process, pulsed laser deposition (PLD), will also be attempted. Temperature of the substrate and PLD pressure will be varied to create an AIN film with piezoelectric behavior.

Subtask 1A: Conduct deposition of thick AIN film by chemical vapor deposition. Nov 2002May 2005. The CVD process continued to produce piezoelectric AlN films in the third year, deposited on porous and siliconized porous SiC, as described above. Deposition of robust films suitable for sensors was not achieved in the program.

Subtask 1B: Identify the promising high temperature substrates with regard to thermal expansion, cost, machinability, and the ability to shape the substrate. Nov 2002-May 2004. The identification of possible substrates was essentially completed in the previous year with the arrangement to procure porous and siliconized porous SiC from Saint Gobain.

Subtask 1C: Experimentally explore the feasibility of AIN deposition onto identified new substrate materials such as graphite, alumina graphite, silicon carbide, titanium diboride, and molybdenum disilicide. January 2003-May 2005. Deposition was achieved on a number of materials in the first two years of the program, and was expanded to the new SiC materials. While the films appeared good and produced adequate ultrasonic signals, they failed to withstand temperature cycling. Microscopic analysis showed that even before cycling, substantial defects were present in the films that likely caused their failure upon heating.

Subtask 1D: Investigate the feasibility of using pulsed laser deposition of the AIN films onto substrates. The substrate pressure and temperature will be varied to determine conditions conducive to producing films specific for this high temperature sensor application. January 2003-January 2004. This subtask was completed in the first year of the program. AlN film deposition using PLD was demonstrated on small areas. The process is not practical for full-scale sensors at this time, but might be useful in the future for the repair of CVD films or for miniature sensors.

\section{Piezoelectric AIN Film Evaluation}

Task Description: An evaluation of films deposited in task 1 will be completed in task 2. The films and high temperature substrates will be characterized structurally and ultrasonically. Characterization of the films will include the adhesion, oxidation, and continuity of the films when exposed to both room temperature and high temperature atmosphere. The ultrasonic properties of the films will also be determined by investigating the frequency, bandwidth, and signal strength at elevated temperatures. Using a scanning electron microscope with $X$-ray diffraction the surface and subsurface of the films will be analyzed to provide data on the crystal structure, defects, and bonding. 
Subtask 2A: Characterize films by examining the thermal and physical properties of the films. Structural evaluation includes adhesion, oxidation, and continuity of the films as a function of time, temperatures up to $1000^{\circ} \mathrm{C}$, and exposure to physical damage. December 2002- June 2005. Characterization to date has included baseline films on tungsten carbide, titanium, and a number of forms of silicon carbide.

The new porous and siliconized $\mathrm{SiC}$ substrates were investigated during the third year of research, but were found to be similar to the better films on monolithic SiC. The film integrity was compromised by exposure to high temperatures.

Subtask 2B: Characterize films by evaluating the ultrasonic properties of the films and substrates. Ultrasonic evaluation includes frequency, bandwidth, and signal strength at ambient and elevated temperatures. December 2002- June 2005. The new AlN films on porous $\mathrm{SiC}$ possessed ultrasonic properties similar to previous films on tungsten carbide and titanium. The acoustic impedance of the porous $\mathrm{SiC}$ matched the AlN much like the monolithic $\mathrm{SiC}$, producing wide bandwidth ultrasonic pulses. The acoustic attenuation of the porous $\mathrm{SiC}$ was good, returning only about $25 \%$ of the energy as solid or siliconized SiC when interrogated by a commercial $10 \mathrm{MHz}$ transducer. Attenuation and scattering is likely to be greater at higher frequencies. Extensive ultrasonic characterization of these films was not performed due to the emphasis on attaining high temperature survival.

Subtask 2C: Characterize films using $x$-ray diffraction and scanning electron microscopy to examine the piezoelectric crystal structure, defects, bonding difficulties, and other material issues. March 2002-December 2004. Earlier analysis indicated that disbands on monolithic SiC were failing cleanly at the AlN-SiC interface. Additional work with the porous substrates revealed the presence of two separate AlN layers. Oxides were discovered on the surfaces where coating failure occurred. Typical results from these analyses are presented above. One additional note is that the as-deposited AlN films exhibit some porosity and through-thickness defects on the microscopic scale.

Subtask 2D: Relate substrate surface preparation to film quality (adhesion, defective areas, film thickness uniformity, and orientation of the piezoelectric crystals). December 2002December 2004. Various surface preparation methods were used on titanium substrates, eventually causing adhesion at room temperature, but not robust enough to overcome the thermal expansion mismatch. Minimal surface preparation of silicon carbide substrates has been required, with good films resulting from no preparation or from polishing and cleaning the asreceived substrate material. Oxidation of the $\mathrm{SiC}$ may be an issue, and the presence of an oxide layer at the surface prior to deposition of the AlN will be evaluated. No relationship has been discovered to date between surface condition and "good" and "bad" areas of a film. Surface preparation also does not appear to have a significant effect on crystal orientation in the films. 


\section{High Temperature Coupling}

Task Description: A literature survey will be made of methods to conduct ultrasonic coupling at elevated temperatures and those that are most suited to equipment health monitoring. Those methods that appear most suited for the application will be verified in the laboratory, in particular, the effect of the coupling layer on the impedance matching will be examined.

Subtask 3A Perform literature survey re high temperature coupling. January 2003-August 2003. This subtask is complete. The literature survey was completed by UDRI with the help of a mechanical engineering student employed as part of our cooperative education program, as summarized in the first year's report. Metal foils and molten glasses were selected as the methods with the highest probability of success and were further evaluated experimentally.

Subtask 3B Design high temperature apparatus for testing films and coupling to test objects. August 2003-December 2003. Based on the literature survey, the technical community appeared to have had limited success in developing ultrasonic coupling methods suitable for use at high temperatures. Accordingly, this subtask was expanded through the second year of the program, and formed the basis of an undergraduate Honors Thesis for the student who performed the literature survey. Results are described in the 2004 annual report.

New results this year are from evaluating artist's gold leaf as a more economical replacement for the gold foil used previously. The same apparatus from the previous tests was used to evaluate the gold leaf. It performed as well or better than the gold foil, comparing favorably with the coupling achieved by a commercial water-based couplant used at room temperature. Figure 17 shows that the initial coupling with the gold leaf is weak, but as the temperature increases, the thin gold leaf quickly conforms to any irregularities at the interface and good coupling is obtained. Coupling is maintained even after cooling the test fixture to room temperature.

Figure 18 shows ultrasonic wavforms with water-based and gold leaf coupling. In addition to operating at high temperatures, the gold leaf appears to better pass the high frequency components of the pulse. The signal through the leaf exhibits ringing initially, but once the gold softens and coupling is achieved, this ringing disappears and a more broadband pulse suitable for testing is obtained. The conclusion is that the gold leaf appears to be an optimal solution to the high temperature coupling problem, if a moderate amount of pressure can be applied.

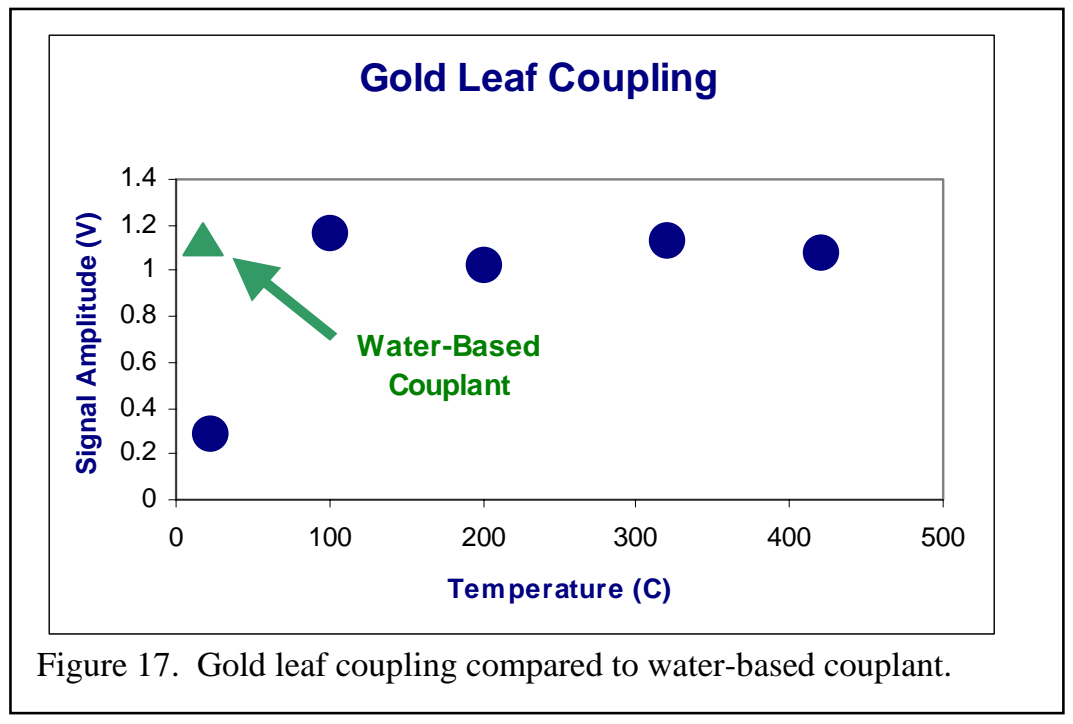




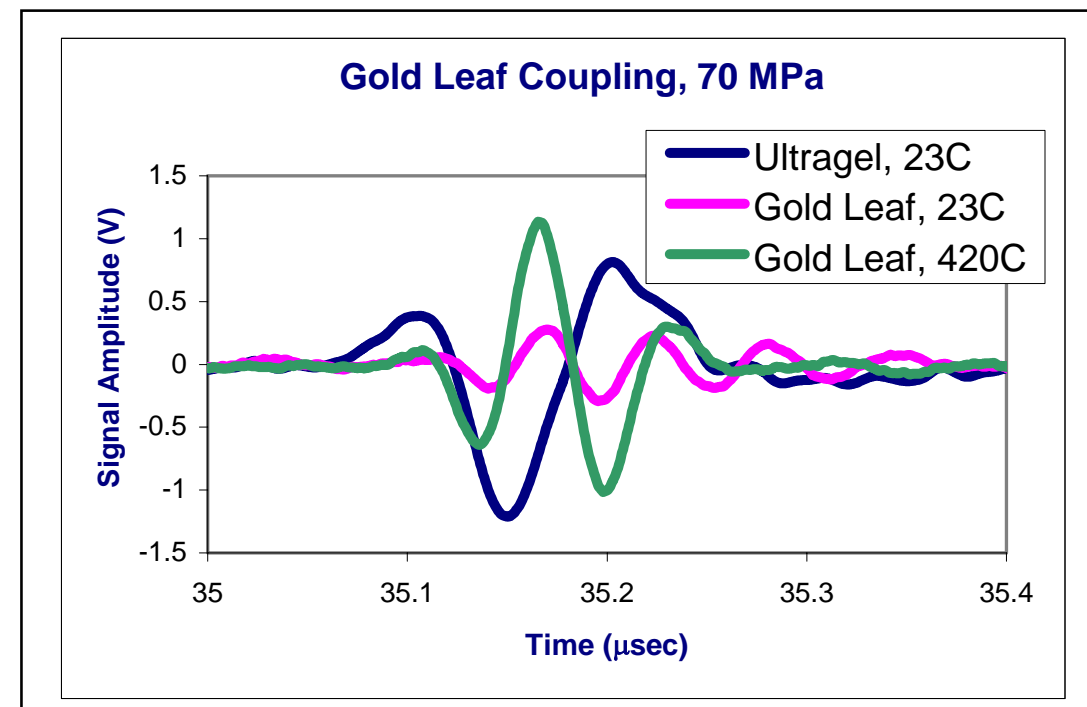

Figure 18. Ultrasonic signals using gold leaf coupling, compared to using water-based couplant.

\section{Equipment Health Monitoring Demonstration}

Task Description: A specific application of an ultrasonic piezoelectric sensor for monitoring equipment health will be selected. Requirements for the specific application will be defined and used to direct the design and fabrication of the sensor. The sensor design will focus on the AIN film, electroding, ultrasonic coupling, high temperature wiring. The feasibility of the sensor will be demonstrated in the laboratory under conditions that simulate the specific application.

Subtask 4A Identify specific application to test AIN film based ultrasonic sensor. Application must be able to be mimicked in the laboratory to demonstrated feasibility of sensor. May 2003- May 2004. Three candidate applications were identified. The first is as a point sensor to monitor the thinning of the inner layer of refractory in a coal gasifier. A sample of a typical gasifier hot face refractory, Zirchrom 90, was obtained from Saint Gobain Ceramics. A commercial $10 \mathrm{MHz}$ contact ultrasonic transducer was used to investigate the ultrasonic properties of the refractory, but no transmission of sound was achieved. Refractory monitoring was discontinued as a candidate application for the ultrasonic sensor. It is possible that much lower frequency $(<1 \mathrm{MHz})$ ultrasound or an impact-echo method might be appropriate to investigate in the future.

A second candidate application was to monitor the condition of a thermal barrier coating applied to a metal part. The third candidate application was to monitor a piece of process equipment such as a heat exchanger. Ultrasonic inspection is commonly performed on such equipment during plant shutdowns. Welds and corrosion-sensitive areas are often trouble sources exhibiting wall thinning or cracking. 
Given the inability to produce usable AlN films for a sensor, the selection of an application was delayed, and finally transformed into a demonstration test using an LGS crystal to monitor the thickness of a test piece of metal, in a furnace environment, with a target temperature of $1000^{\circ} \mathrm{C}$.

Subtask 4B Set up laboratory for feasibility demonstration. May 2004- December 2004. Setup for the above test involved a simple assembly of a Satec SF-16 tube furnace, 2 BarberColman 560 furnace controllers, The Utex 340 pulser-receiver, and an Agilent 54622A oscilloscope.

Subtask 4C Design and fabricate sensor specific to the application including the AIN film, electroding, ultrasonic coupling, and high temperature wiring. May 2004-June 2005. Earlier design work based on an AlN film transducer applies for the most part. Inside the furnace are test blocks, thermocouples, and an LGS crystal. Gold ink, again borrowed from the art world, will take the place of gold leaf for couplant and electroding. Thermocoax high temperature coaxial cable will transmit the signal out of the hot zone of the furnace. A sialon block will be tested as a transducer backing. High temperature ceramic springs made from silicon nitride or toughened zirconia were identified for this phase but will not be used because of the scaled-down demonstration.

Subtask 4D Evaluate performance of sensor system at elevated temperatures $\left(700-1000^{\circ} \mathrm{C}\right)$ in selected application. December 2004- August 2005. The demonstration test will occur early in 2006, after the pulser-receiver has been repaired; test data will be presented in the final report. 


\section{SECTION 5 \\ CONCLUSIONS}

Piezoelectric AlN film deposition was successfully transferred from tungsten carbide to other substrate materials, including titanium, conductive bulk AlN, and various forms of SiC. None of these films were robust enough to withstand the require temperature excursions for a successful sensor. Similarly, pulsed laser deposition of AIN was demonstrated, but is not practical for ultrasonic sensor fabrication. The AIN films are not recommended for further investigation for general purpose sensors, although there may be some niche applications requiring high frequency ultrasound and intermediate temperatures that may be appropriate.

Many of the auxiliary issues for sensor construction were identified and addressed during the program, most notably the issue of high temperature ultrasonic coupling. Coupling using thin metal foils under pressure was very successful, with sound transmission at or above the levels provided by traditional water based couplants at room temperature. Gold leaf was selected as the optimum foil in terms of performance and cost. An alternative to AlN films, single crystal langasite, was identified during the program; preliminary data indicates it holds promise for the targeted sensor applications. Advantages include oxidation resistance and ready commercial availability in thick (low frequency) sections.

Dissemination of research results to date has included:

- A student senior Honors thesis and associated presentation: “Coupling for High Temperature Ultrasonic Testing”, Michael Frede, 2005.

- Technical Presentation: " Piezoelectric Aluminum Nitride Film Transducers for UltraHigh Temperature Ultrasonics ", James Sebastian, Michael Frede, David Stubbs. 25th QNDE, Brunswick, ME, August 2005.

- Poster Presentation: “Ultrasonic Coupling for High Temperature Health Monitoring” James Sebastian, Michael Frede. 25th QNDE, Brunswick, ME, August 2005.

- Technical Presentation: "Recent Advances in Piezoelectric Aluminum Nitride Ultrasonic Transducers for High Temperature Health Monitoring and Inspection” James Sebastian, Michael Frede. ASNT Fall Conference, Columbus, OH, October 2005.

Additional opportunities to present and publish this work will be pursued in the coming year. 